\title{
Citation:
}

O'Kelly B.C. and Naughton P.J. 2008. Local measurements of the polar deformation response in a hollow cylinder apparatus. Geomechanics and Geoengineering, Vol. 3, No. 4, 217-229'

\section{Local measurements of the polar deformation response in a hollow cylinder apparatus}

\section{Brendan C. O'Kelly}

Lecturer

Department of Civil, Structural and Environmental Engineering

Museum Building, Trinity College Dublin, Dublin 2, Ireland.

Tel. 00353 18962387, fax. 00353 16773072, E-mail: bokelly@tcd.ie

\section{Patrick J. Naughton}

Lecturer

School of Engineering

Institute of Technology, Sligo

Ballinode, Sligo, Ireland.

Tel. 0035371915 5489, fax.00353 71915 5390, E-mail: naughton.patrick@itsligo.ie

\section{Corresponding author: Brendan O'Kelly}

First submission: 08th February 2008.

Resubmission: 24th June 2008. 


\begin{abstract}
This paper describes the set up, calibration and performance of the local instrumentation that measures the deformation response of the test-specimen in a new hollow cylinder apparatus (HCA). Customised, single and double-axes inclinometers measure the axial and twist deformations of the outer specimen wall surface. Proximity transducers in the cell chamber and the specimen bore cavity measure the radial wall surface displacements and precision gearing allows the relocation of the transducers from outside the pressure-cell. The inclinometers were modified (reduced gauge of $45 \mathrm{~mm}$ ) to suit the smaller-sized test specimen and the more compact pressure cell of the HCA. The instruments were calibrated using an optical table and laser distance-measurement system to achieve the necessary accuracy for strain measurements over the pseudoelastic range. The calibration in water of the proximity transducers was non-linear and strongly influenced by the specimen wall curvature. Equations are presented to compute the true torsional shear strain response from the measured inclinometer tilt angle, specimen dimensions and deformation response. External measurements include significant errors due to apparatus compliance; specimen end-restraint and bedding effects; inaccuracies in measuring volume changes and the fact that the deformations are calculated assuming that the entire specimen deforms as a right cylinder.
\end{abstract}

Keywords: Calibration; Deformation; Hollow cylinder apparatus; Instrumentation; Measurement; Strain

\title{
1. Introduction
}

It is now widely recognised that the load-deformation response of a geomaterial specimen in the triaxial apparatus should be measured using local instrumentation for an accurate assessment of the small-strain stiffness response. Measurement errors due to apparatus compliance and specimen end-restraint and bedding effects are excluded when the deformation response is measured within the mid-third of the specimen length, with a typical aspect (height to diameter) ratio of two (Jardine et al. 1984; Baldi et al. 1988). Many innovative techniques have been developed to measure the deformations locally including displacement transducers LVDTs (Cuccovillo and Coop 1997; Huang et al. 2007); electrolevel inclinometers (Jardine et al. 1984; Symes and Burland 1984); Hall-effect transducers (Clayton and Khatrush 1986); image analysis (Rechenmacher and Finno, 2004) as well as non-contacting electromagnetic techniques, e.g. proximity transducers (Brown et al. 1980; Symes and Burland 1984; Hird and Yung 1989; Lo Presti et al. 1993; Menkiti 1995). The attachment of the instruments to the specimen wall surface may influence the deformation response, in particular during dynamic load testing, and proximity transducers which have been successfully used for many applications in geotechnical laboratory testing offer a particular advantage in this respect.

In particular, Hight et al. (1983) incorporated six electrolevel-inclinometers and a series of proximity transducers in the large Imperial College (IC) hollow cylinder apparatus 
(HCA) to measure the deformation response of the hollow cylindrical test-specimen (101.5 mm inner radius, $127.0 \mathrm{~mm}$ outer radius and $254 \mathrm{~mm}$ in overall length). Two inclinometers configurations were used to measure the axial and twist deformations while pairs of proximity transducers measured the radial displacements of the specimen wall surfaces.

The technology of proximity transducers is well developed and a wide range of equipment is commercially available. The transducers use the principal of impedance variation (eddy-current loss) to measure the gap between the transducer face and an aluminium foil target that has been attached to the rubber membrane enclosing the specimen wall surface. The transducer coil constitutes one leg of a balanced Wheatstone bridge circuit. The bridge network senses changes in the impedance of the transducer coil as the foil target moves within the electromagnetic field and the data is converted to an analogue voltage by a signal-conditioning unit. The foil target (less than $0.02 \mathrm{~mm}$ in thickness) is attached during specimen set up by smearing the contact area with the rubber membrane with silicone grease (preventing any reinforcement effect) and is pressed in full contact against the specimen membrane during the test by the applied confining pressures. The displacement of the membrane, and hence the foil target, matches that of the specimen wall surface during a test (Tatsuoka et al. 1983).

The inclinometers comprise electrolevels sealed inside stainless-steel capsules that are mounted on linkage mechanisms. The linkages are attached at two points to the rubber membrane enclosing the outer specimen wall surface using high-strength contact glue to secure the miniature attachment pads. The electrolevels themselves comprise three coplaner electrodes that are partially immersed in an electrolyte contained inside a sealed glass receptacle (Burland and Symes 1982). Relative axial and circumferential displacements of the inclinometer attachment-pads during a test cause tilting of the electrolevel in the radial and circumferential directions, respectively. Since the movements of the outer membrane and the outer wall surface are coincident (Tatsuoka et al. 1983), the axial and twist deformations of the specimen can be related to changes in the electrical resistances measured between the central and outer electrodes of the electrolevels. The size of the void space in the electrolevel capsules is such that the inclinometers have zero buoyant weight in-service and the specimen deformation response is, therefore, unaffected by the attachment of the inclinometers.

Although theoretically sound, the local instrumentation set up of inclinometers and proximity transducers used by Hight et al. (1983) in the large IC HCA is difficult to implement unless the outer specimen radius is at least $100 \mathrm{~mm}$ (Huang et al. 2007). This paper describes the set up, calibration and performance of the customised inclinometers and proximity transducers that measure the local deformation response of a smaller testspecimen $(35.5 \mathrm{~mm}$ inner radius; $50.0 \mathrm{~mm}$ outer radius and $200 \mathrm{~mm}$ in overall length, $\mathrm{H})$ commonly used in several HCA currently available in a few research laboratories in the world, including University College Dublin (UCD).

The development, instrumentation and set up of the UCD HCA have been reported by O'Kelly (2000); O'Kelly and Naughton (2003; 2005b), Figure 1. Independently controlled confining pressures, $\mathrm{p}_{\mathrm{o}}$ and $\mathrm{p}_{\mathrm{i}}$, are applied to the outer cell chamber and the inner bore cavity of the hollow cylindrical test-specimen, respectively (Figure 2(a)). 
Axial (W) and torsional (T) loads are applied via ribbed, sintered-bronze disc in contact with the lower end of the specimen which is fully restrained at its upper end.

The axial and twist specimen deformations are calculated on the basis of the inclinometer tilt angle measured in the circumferential direction along an arc of radius $r_{\text {incl }}$ corresponding to the centre of the electrolevel capsules (i.e. beyond the outer specimen wall surface). A series of equations, which build upon existing formulations reported by IC researchers (including Symes and Burland (1984)), are developed to compute the true torsional shear strain response for the UCD inclinometer configurations. Other objectives include: (a) Development of data-acquisition hardware and calibration procedures to achieve the necessary resolution and accuracy for strain measurements over the pseudo-elastic range (strain levels less than $10^{-5}$ strain); (b) Study the effects of the specimen wall curvature and the operating environment (in air or submerged in water) on the transducer calibration and (c) Assess the source and magnitude of the error in the deformations recorded using instrumentation external to the pressure cell. The relative performance of the local and external instrumentation was assessed by performing a generalised stress path test on a fully saturated sand specimen in the UCD HCA.

Figure 1

Figure 2 (a) and (b)

\section{Measurement of deformation response in UCD HCA}

Local instrumentation measures the polar deformation response over the uniformly stressed zone within the mid-third of the specimen length in the UCD HCA (Naughton and O'Kelly 2007). It is convenient to use a polar coordinate system in considering the states of stress and the deformation/strain response. Three electrolevel-inclinometers are used to measure the axial (w) and twist $(\theta)$ deformations while two proximity transducers measure the radial displacements of the outer and inner specimen wall surfaces, $u_{o}$ and $u_{i}$, respectively (Figure 2(b)). One proximity transducer is located in the outer cell chamber while the second is located directly opposite, inside the specimen bore cavity (Figure 3 ).

Figure 3

The inclinometers used in the present study were of the type originally developed to measure the local axial deformation of triaxial test-specimens (Burland and Symes 1982; Jardine et al. 1984) and which were further developed by Symes and Burland (1984) to measure the local axial and twist deformations of test-specimens in the IC HCA (Hight et al. 1983). In the UCD set up, one single-axis and two double-axes inclinometers provide two axial and three twist deformation measurements of up to 20 
$\mathrm{mm}$ and 30 degrees, respectively, around the outer specimen wall surface (Figure 4). The two double-axis inclinometers are located diametrically apart and the single-axis inclinometer is located midway between the double-axis inclinometers around the outer wall surface.

Figure 4 (a) and (b)

The single-axis inclinometer (Figure 4(a)) comprises a single electrolevel capsule mounted on a mechanical linkage that facilitates sliding of the capsule in the axial direction, thereby simply measuring the twist deformation response. The double-axes inclinometer, which is used to measure both the axial and twist deformations, comprises two electrolevel capsules mounted on a mechanical linkage (Figure 4(b)). The configuration of the linkages was modified in the UCD setup to reduce the initial gauge, $\mathrm{L}_{\mathrm{zi}}$ (nominally $120 \mathrm{~mm}$ in the Symes and Burland (1984) design) to $45 \mathrm{~mm}$ in length. The reconfiguration was necessary to facilitate free movement of the linkages as the specimen deformed axially and to ensure that the deformation response was measured within the mid-third of the specimen length. This was achieved by relocating the inclinometer legs, which attach the instrument to the outer specimen membrane, from the outermost to the innermost ends of the electrolevel capsules (Figure 4(b)).

Measurements of the overall deformation response are also recorded using instrumentation located outside the pressure cell (O'Kelly 2000; O'Kelly and Naughton 2005b). The axial and twist deformations are measured over the full specimen length using two displacement transducers and an optical rotary encoder, respectively (O'Kelly 2000; O'Kelly and Naughton 2005b). The radial displacements of the inner and outer specimen wall surfaces are calculated from the volume changes of the specimen and its inner bore cavity (independently measured by pressure-volume controllers supplied by GDS Instruments Ltd., UK).

\section{Set up of proximity transducers in the UCD HCA}

The radial displacements of the specimen wall surfaces are measured using two proximity transducers (type 6U-unshielded supplied by Kaman Instrumentation Corporation, USA), which have a $6.0 \mathrm{~mm}$ measurement range and a recommended offset distance at zero measurement range of between 0.6 and $1.2 \mathrm{~mm}$ (gap between the transducer face and the foil target attached to the specimen membrane). The transducers can be located at different levels (although usually at the specimen mid-height, Figure 3 ) prior to sealing the inner bore cavity during specimen setup. An allowance is made in sizing the foil target to accommodate the anticipated relative movements between the transducer face and the specimen wall surface during the course of the test. The gap between the transducer face and the foil target is also adjusted to accommodate the anticipated deformation response. The transducers and right-angled cable connectors are electrically insulated inside compact uPVC housings which are assembled using nylon screw fasteners (Figure 5). 
Figure 5

A special micro-seal waterproofing treatment was applied to the transducer face. The coaxial cables ( $3.0 \mathrm{~m}$ in length) from the proximity transducers form an integral part of the Wheatstone bridge circuit and are sealed inside thick-walled plastic tubing that exits through the top plate of the pressure cell. Hand-tightened nylon ferrules, rubber O-rings and Dowty-bonded seals hydraulically seal the transducer housing, which had been specially profiled such that the assembly fitted neatly inside the specimen bore cavity and allowed a uniform contraction of up to $9.4 \mathrm{~mm}$ in the inner wall radius. Moreover, the combined buoyant weight of the transducer and its housing was negligible.

The locations of the transducers can be adjusted from outside the pressure cell using precision gearing (operated by a lever and locking device from above the cell top-plate) to suit the specimen deformation response during the course of a test. The outer proximity transducer housing is supported by an articulated arm from a vertical rod (Figure 6). Meshing double-helical gears secure the upper end of the rod against the cell top-plate and facilitate fine readjustments of the housing location. Figure 7 shows the mechanism that is operated thought the reaction platen assembly to locate the inner proximity transducer inside the specimen bore cavity.

Figure 6

\section{Figure 7}

During the assembly of the apparatus, the inner proximity transducer is positioned perpendicular to the inner wall surface at the mid-height of the specimen before the bore cavity is sealed by securing the specimen top-cap to the reaction platen (Figure 7). Compression O-rings seal the specimen and its inner bore cavity and vibration proof the mechanism, which is operated from above the cell top-plate by a lever and gearing (rack and pinion). A precision guide maintains the vertical alignment of the elbow that supports the transducer housing. Novel design features are that neither the outer cell chamber nor the specimen bore cavity experience a volume change because of relocating the inner proximity transducer during the course of a test. Moreover, the net horizontal force acting on the mechanism is zero (even when different outer and inner confining pressures are applied) since the gearing mechanisms and elbow components have equal cross-section areas through the reaction platen.

\section{Calculation of strain response}

This section presents the equations for the non-zero strain components developed across the specimen wall thickness. The non-zero stress equations have been reported in detail by O'Kelly and Naughton (2005a,b,c) and Naughton and O'Kelly (2007). The mean non-zero strain components are calculated from the local radial $\left(\mathrm{u}_{\mathrm{o}}, \mathrm{u}_{\mathrm{i}}\right)$, axial $(\mathrm{w})$ and twist $(\theta)$ deformations measured using the proximity transducers and the inclinometers 
Andover an axial gauge length, $\mathrm{L}_{z}$ (Eqs. 1-4). Similar equations have been reported for strain calculations in other HCAs by Ampadu and Tatsuoka (1993); Hight et al. (1983); Miura et al. (1986) and Vaid et al. (1990). The mean axial normal strain $\left(\overline{\varepsilon_{z}}\right)$ was assumed to be uniform over the annular cross-section area of the specimen wall. The mean radial and circumferential normal strains $\left(\overline{\varepsilon_{r}}\right.$ and $\overline{\varepsilon_{\theta}}$, respectively) are calculated from the radial wall displacements $\left(\mathrm{u}_{\mathrm{o}}, \mathrm{u}_{\mathrm{i}}\right)$ assuming a linear variation in the radial displacement that develops across the specimen wall thickness. The mean torsional shear strain $\left(\overline{\gamma_{z \theta}}\right)$ is averaged over the cross-section area of the specimen wall.

$$
\begin{aligned}
& \overline{\varepsilon_{z}}=\frac{w}{L_{z}} \\
& \overline{\varepsilon_{r}}=-\left(\frac{u_{o}-u_{i}}{r_{o}-r_{i}}\right) \\
& \overline{\varepsilon_{\theta}}=-\left(\frac{u_{o}+u_{i}}{r_{o}+r_{i}}\right) \\
& \overline{\gamma_{z \theta}}=\frac{2 \theta\left(r_{o}^{3}-r_{i}^{3}\right)}{3 L_{z}\left(r_{o}^{2}-r_{i}^{2}\right)}
\end{aligned}
$$

where $r_{i}$ and $r_{o}$ are the radii of the inner and outer specimen wall surfaces, respectively, at the start of the stress path test and $\theta$ is the twist deformation that occurs over the axial gauge length $\mathrm{L}_{z}$ (the vertical distance between the inclinometer attachment points). Note that radius $r_{o}$ is measured to $0.1 \mathrm{~mm}$ using $\pi$ tape and radius $r_{i}$ is calculated from the recorded water depth produced by filling the inner bore cavity with a known volume of water using the pressure-volume controller during specimen set up (O'Kelly and Naughton 2005b,c).

\section{Calculation of torsional shear strain}

The twist deformation $(\theta)$ that occurs over the gauge length $\mathrm{L}_{z}$ is related to the inclinometer tilt angle $\phi_{\text {incl, }}$, which is measured in the circumferential direction, and beyond the specimen outer wall surface, along an arc of radius $r_{i n c l}$ : the radial distance from the specimen axis to the point of measurement at the central electrode of the electrolevel capsule (Figure 8). In general, the radius $r_{\text {incl }}$ is a function of the specimen dimensions and axial deformation; the inclinometer geometry and the initial gauge length. Referring to Figure 8, the twist $\theta$ that occurs over the gauge length $\mathrm{L}_{z}$ can be related to the circumferential tilt angle $\phi_{\text {incl }}$ as:

Figure 8 
$\theta=\frac{L_{z} \tan \phi_{i n c l}}{r_{\text {incl }}}$

The outer radius $r_{o}$ is directly measured by the outer proximity transducer during the course of a test whereas the inclinometer radius $r_{\text {incl }}$ is not. Connolly and Kuwano (1999) noted that it would be incorrect to calculate the twist of the specimen based on the measured radius $r_{o}$, instead of the inclinometer radius $r_{\text {incl }}$, in Eq. (5). A series of equations are derived in the present study to calculate the true torsional shear strain response from the measured radius $r_{o}$ and inclinometer tilt $\phi_{\text {incl }}$ for the UCD set up. The equations take into consideration the specimen dimensions and axial deformation response; the initial gauge length and the geometry and articulation of the inclinometer linkages as the specimen deforms under loading. Figure 9 shows the arrangement of the UCD double-axes inclinometers (symmetry about hinge at point $a$, Figure 9), which have set dimensions of $\mathrm{A}=25.0 \mathrm{~mm}, \mathrm{~B}=50.0 \mathrm{~mm}$ and $\mathrm{C}=45.0 \mathrm{~mm}$.

Referring to Figure 9, the inclinometer radius $r_{\text {incl }}$ is given by:

Figure 9

$$
r_{\text {incl }}=d+r_{o}
$$

where $d$ is the distance from the outer specimen wall surface to the centre of the electrolevel capsule and $r_{o}$ is the outer specimen radius, which is continuously measured by the outer proximity transducer during the course of a test.

The distance $d$ changes as the specimen deforms axially and is directly related to the gauge length $\mathrm{L}_{\mathrm{z}}$. However, the distance $\mathrm{d}$ is independent of any relative twist that may occur between the inclinometer attachment points due to the configuration of the linkages. The gauge length is calculated during the course of a test as the difference between the initial gauge length $\left(\mathrm{L}_{\mathrm{zi}}\right.$ : measured to $0.01 \mathrm{~mm}$ during specimen set up using Vernier callipers) and the axial deflection (h) which is directly measured by the inclinometer:

$$
L_{z}=L_{z i}-h
$$

The gauge length and the distance $\mathrm{d}$ are both functions of the inclinometer tilt $\delta$ that occurs in the radial direction (Figure 9). Hence, an expression can be developed to relate the inclinometer radius $r_{i n c l}$ and the axial deflection $h$. The distance from the hinge (point a in Figure 9) to the outer specimen wall surface is given by:

$$
\left|a e^{\prime}\right|+\left|e^{\prime} g\right|=\left|a b^{\prime}\right|+|b f|
$$


From trigonometry, the distance $d$ is related to the gauge length $L_{z}$ and the radial tilt angle $\delta$ by:

$d=\left|e^{\prime} g\right|=\frac{L_{z} \tan \delta}{2}+\frac{C}{\operatorname{Cos} \delta}-B \operatorname{Sin} \delta$

An expression can also be developed between the gauge length $\mathrm{L}_{z}$ and the angle $\delta$. Referring to Figure 9:

$$
A=|a b|+|b c|
$$

Again, from trigonometry, the gauge length $\mathrm{L}_{\mathrm{z}}$ is related to the angle $\delta$ by:

$$
L_{z}=2(A \operatorname{Cos} \delta-C \operatorname{Sin} \delta)
$$

In general, the radial tilt angle $\delta$ can be simply expressed as a function of the gauge length $L_{z}$ by rearranging Eq. (11). The distance $d$ can then be expressed as a function of the gauge length $\mathrm{L}_{\mathrm{z}}$ alone by substituting this relationship for the radial angle $\delta$ in Eq. (9). The general equation relating the inclinometer radius $r_{\text {incl }}$ and the measured distances $r_{o}, L_{z i}$ and the axial deflection $h$ is obtained by substituting for the distance $d$ in Eq. (6) and expressing the gauge length $\mathrm{L}_{\mathrm{z}}$ in terms of its initial value $\left(\mathrm{L}_{\mathrm{zi}}\right)$ and the deflection h, Eq. (7). For example, Figure 10(a) and Eq. (12) give the relationship between the tilt angle $\delta$ and the gauge length $\mathrm{L}_{\mathrm{z}}$ for the double-axes inclinometers (calculated based on the set UCD dimensions of $\mathrm{A}=25.0 \mathrm{~mm}$ and $\mathrm{C}=45.0 \mathrm{~mm}$ ).

$\delta=-0.58 L_{z}+29.3$

Figure 10 (a) and (b)

Substituting Eq. (12) back into Eq. (9), and setting B $=50.0 \mathrm{~mm}$ and $\mathrm{C}=45.0 \mathrm{~mm}$, gives the relationship between the distance $d$ and the gauge length $L_{z}$ (Figure 10(b)):

$d=0.35 L_{z}+27.9$

Finally, the expression relating the inclinometer radius $r_{\text {incl }}$ and the measured outer radius $r_{o}$, initial gauge $L_{z i}$, and axial deflection $h$ is obtained by substituting Eqs. ( 7 and 13) back into Eq. (6): 
$r_{\text {incl }}=r_{o}+(0.35)\left(L_{z i}-h\right)+27.9$

In the case of the single-axis inclinometer, the linkage operation is such that the single electrolevel capsule (Figure 4(a)) simply measures the relative twist between the inclinometer attachment pads. The distance $d$ from the specimen outer wall surface to the centre of the electrolevel capsule remains constant, irrespective of the specimen deformation response. Hence, in this particular case, the inclinometer radius $r_{\text {incl }}$ and the outer specimen radius $r_{o}$ are simply related by Eq. (6). The distance $d$ was set at 15.0 $\mathrm{mm}$ for the UCD set up.

\section{Data acquisition and control}

The local instrumentation interfaces with the control computer via a dedicated 24-bit data-acquisition (DAQ) unit NI4350 from National Instruments for closed-loop control in targeting a generalized stress path in the UCD HCA. The 24-bit DAQ unit provided the necessary resolution for deformation measurements in the pseudo-elastic range (strain levels $<10^{-5}$ strain). The coaxial cables from the instruments were connected in differential mode to a general-purpose terminal block (National Instruments, TBX68) that was in turn connected to the DAQ unit by a shielded cable, $1.0 \mathrm{~m}$ in length, also supplied by National Instruments. The DAQ unit, which had eight differential inputs at rates of 2.8, 8.8 and 9.7 readings/s in multi-acquisition mode, was connected via a USB port to the control computer.

The closed-loop control of the apparatus using a suite of LabVIEW® programs to target a prescribed effective stress path and accurately measure the deformation response has been reported by O'Kelly and Naughton (2005a). The equations relating the inclinometer radius $r_{\text {incl }}$ to the measured outer specimen radius $r_{o}$ and the circumferential inclinometer tilt $\phi_{\text {incl }}$ (Eqs. 6-14) were incorporated in the control code. Corrections were also applied in the code for the effects of membrane restraint and membrane penetration on the measured deformation response using the methods developed by Tatsuoka et al. (1986) and Sivathayalan and Vaid (1998), respectively.

Table 1 lists the range, resolution and output values of the local instrumentation. The electrolevels were powered at $5 \mathrm{~V}$ and outputted $50 \mathrm{mV} / \mathrm{mm}$ axial deformation and 50 $\mathrm{mV}$ per three-degree twist, which facilitated axial normal and torsional shear strain measurements of the order of $10^{-5}$ strain. The proximity transducers have a full-scale output of $\pm 5.0 \mathrm{~V}$ so that the DAQ unit can resolve the output to $1.1 \times 10^{-6} \mathrm{~mm}$ (more than an order of magnitude improvement in the measurement resolution reported in the geotechnical literature (Hird and Yung 1989; Scholey et al. 1995; Lo Presti et al. 1993) for similar setups (measurement ranges of 2.5-5.0 $\mathrm{mm}$ ).

Table 1 


\section{Calibration}

The inclinometers and proximity transducers were calibrated using an optical table and a laser distance-measurement system to achieve the necessary measurement accuracy over the pseudo-elastic range. The optical table allowed set displacements to a resolution of $0.0025 \mathrm{~mm}$ in three orthogonal directions. The laser distance-measurement system had resolution and accuracy values of the order of $10^{-9}$ and $10^{-8} \mathrm{~mm}$, respectively (Figure 11).

Figure 11

The inclinometers were calibrated, firstly, for axial displacement alone and twist displacement alone and secondly for interaction between the axial and twist displacement outputs. The double-axis inclinometers were calibrated, firstly, for axial displacement alone and twist displacement alone and secondly for interaction between the axial and twist displacement outputs. The axial displacement $h$ and the circumferential tilt angle $\phi_{\text {incl }}$ of the electrolevel capsules were set to resolutions of $0.0025 \mathrm{~mm}$ and 0.003 degrees (corresponding to axial and torsional strain resolutions of $1.3 \times 10^{-5}$ and $4.5 \times 10^{-5}$ strain, respectively) using the optical table. The calibration data indicated that the outputs from the double-axis inclinometers were linear for axial displacement $h$ alone (Figure 12(a)) and for tilt displacement $\phi_{\text {incl }}$ alone over the measurement range of $-12^{\circ} \leq \phi_{\text {incl }} \leq 7^{\circ}$ (Figure 12(b)). In the latter case, the bottom attachment pad was moved horizontally relative to the top attachment pad, causing the capsules to tilt through an angle $\phi_{\text {incl }}$, but without any axial displacement occurring. The interaction between the axial and twist displacement outputs was then studied by simultaneously varying both parameters. The linearity of the calibration data facilitated multi-linear regression analysis of the inclinometer data recorded during generalized stress path testing in the UCD HCA (simultaneous axial and twist deformations). The interaction coefficients for multi-linear regression analysis of the axial and twist displacements ranged between $1.9 \%$ and $29.4 \%$ indicating that significant interaction occurred between the outputs. Failure to account for this interaction could manifest as an error of up to $30 \%$ in the measured values. The calibration data also indicated that the output from the single-axis inclinometer was linear over the twist measurement range of $-10^{\circ} \leq \phi_{i n c l} \leq 10^{\circ}$ Figure $\left.12(\mathrm{c})\right)$.

Figure 12 (a) and (b) and (c)

The proximity transducers were mounted in their UPVC housings and calibrated while submerged in water (in-service condition) since the transducer response has been shown to be affected by its operating environment (Menkiti 1995). Calibration in water produces a different response to calibration in air since water is a polar fluid and hence the transducer output is influenced by the dielectric constant for water. However, the transducer response is not affected by the range of confining pressures ( 0 to $2 \mathrm{MPa})$ that are applied in the UCD HCA. The transducer housings were fully submerged under water at atmospheric pressure and set up on the optical table. The targets were aluminium foil that had been secured to two uPVC discs (with the same curvatures as 
the inner and outer wall surfaces of the UCD test-specimen) using silicone grease. The transducer face was moved normal to the foil target and the actual displacement that had occurred was precisely measured using the laser system. The tests and calibration procedures were carried out in a temperature-controlled environment at $20 \pm 2^{\circ} \mathrm{C}$. Figure 13 shows some typical calibration data for the outer and inner proximity transducers (convex and concave targets, respectively).

Figure 13

The proximity transducers were calibrated to a measurement accuracy of $1.0 \times 10^{-5} \mathrm{~mm}$, which corresponds to radial and circumferential normal strain accuracy values of about $7 \times 10^{-7}$ strain (calculated using Eqs. 2-3 for the UCD specimen dimensions). The transducer responses were both non-linear and best fitted by fourth order polynomials $\left(\mathrm{R}^{2}=0.9999\right)$ using the method of least squares (similar approach used by Hird and Yung (1989)). The calibration equations were also coded and used in the UCD HCA control program (O'Kelly and Naughton 2005a). The measurement accuracy was found to be $0.1 \%$ of the full-scale output and hence the accuracy can be improved further, if necessary, by calibrating the transducers over a smaller measurement range and, in the case of the outer proximity transducer (convex target), by reducing the transducer offset distance (Kaman Instrumentation Corporation 1986). Such improvements are desirable from a control standpoint in conducting stress path testing and measurements over the pseudo-elastic range. For example, the torsional shear stress value induced in the specimen under the action of an applied torque is particularly sensitive to the radial displacements of the specimen wall surfaces (Hight et al. 1984).

A second series of calibration tests were performed in which the proximity transducers were calibrated in air to assess the magnitude of the error that could arise. Figure 14 shows that the data for calibration in air and in water differed by about $0.09 \mathrm{~mm}$ over the measurement range of 0.5 to $5.0 \mathrm{~mm}$, and corresponds to a measurement error of $1.5 \%$ full scale, which is significant, particularly in the determination of the small-strain stiffness response of geomaterials. Note that Menkiti (1995) also found that different calibration curves were obtained for calibration of a proximity transducer $(9.5 \mathrm{~mm}$ range) in air and in water although the magnitude of the reported error was slightly greater than that for the UCD setup $(6.0 \mathrm{~mm}$ range) due to its larger measurement range.

Figure 14

The electrical stability of the transducer outputs with elapsed time was also assessed by recording the output voltage at $5 \mathrm{~min}$ intervals over a 24-hour period before the start of each stress path test. Longer-term stability checks were also carried out. The standard deviation was significantly less than $0.5 \%$ of the mean output voltage, which was considered adequate. 


\section{Stress path testing}

The performance of the local instrumentation was proven by following a generalised stress path using the UCD HCA. The local and external deformation measurements are compared and the error that would arise in incorrectly calculating the torsional shear strain value based on the measured outer specimen radius $r_{o}$ instead of inclinometer radius $r_{\text {incl }}$ in Eq. (2) was assessed.

A fully saturated test-specimen $(35.5 \mathrm{~mm}$ inner radius, $50.0 \mathrm{~mm}$ outer radius and 200 $\mathrm{mm}$ in overall length) of white Leighton Buzzard sand was prepared in the UCD HCA using a wet pluviation technique (O'Kelly and Naughton 2005c) and densified to an initial void ratio of 0.58 , which corresponds to a relative density of $70.8 \%$ (dense state). The specimen preparation technique produces an inherent cross-anisotropic fabric (Naughton and O'Kelly 2003; 2004) and the geoengineering properties of the Leighton Buzzard sand (clean, medium-sized sand comprising sub-angular grains) have been reported elsewhere by O'Kelly and Naughton (2005b, c). The test-specimen was isotropically consolidated to a mean effective confining stress p' of $200 \mathrm{kPa}$ and fully saturated against an applied backpressure of $150 \mathrm{kPa}$ (achieving a pore pressure coefficient $\mathrm{B} \cong 0.99$ ). The specimen was then anisotropically consolidated following a stress path that comprised four stages as follows:

Stage 1. The effective stress ratio R' (Eq. 15) and the intermediate principal stress parameter $b$ (Eq. 16) were linearly increased from $R^{\prime}=1.0$ to 1.5 , and $b=0.0$ to 0.5 , with p' remaining constant at $200 \mathrm{kPa}$.

Stage 2. The orientation of the major principal stress $\left(\alpha_{\sigma}\right)$ was smoothly rotated from $\alpha_{\sigma}=0^{\circ}$ (vertical direction) to $\alpha_{\sigma}=45^{\circ}$, with the values of p', R' and the $b$ parameter remaining constant.

Stage 3. The R' value was increased again from $\mathrm{R}^{\prime}=1.5$ to 2.5 , with the values of $\mathrm{p}$, $\alpha_{\sigma}$ and the $b$ parameter remaining constant.

Stage 4 . The principal stress difference $\left(\sigma_{1}{ }^{\prime}-\sigma_{3}\right.$ ') was increased by smoothly increasing the torsional shear stress value from $85 \mathrm{kPa}$ (applied at the end of stage 3) to $157 \mathrm{kPa}$, at which point the specimen failed in shear.

$$
\begin{aligned}
& R^{\prime}=\frac{\sigma_{1}^{\prime}}{\sigma_{3}^{\prime}} \\
& b=\frac{\sigma_{2}^{\prime}-\sigma_{3}^{\prime}}{\sigma_{1}^{\prime}-\sigma_{3}^{\prime}}
\end{aligned}
$$

where $\sigma_{1}^{\prime}, \sigma_{2}^{\prime}$ and $\sigma_{3}^{\prime}$ are the major, intermediate and minor principal effective stresses that are calculated from the non-zero stress components.

The stress path was followed by stepping between a series of intermediate target stress points located along the prescribed stress path (O'Kelly and Naughton 2005a). The 
smooth control achieved for the torsional shear stress $\left(\tau_{z \theta}\right)$ and the effective normal stresses induced in the axial $\left(\sigma_{\mathrm{z}}\right)$, radial $\left(\sigma_{\mathrm{r}}\right)$ and circumferential $\left(\sigma^{\prime}{ }_{\theta}\right)$ directions are shown in Figure 15 (actual values of the mean stress components were within $2.5 \%$ of the targeted values). The control program calculated the states of stress and strain in the test-specimen based on the applied loads and confining pressures and the deformation response measured by the local instrumentation. O'Kelly and Naughton (2005b) have shown that the axial strains calculated from the external deformation measurements are in reasonable agreement with the true values measured locally by the inclinometers. Figure 16 shows the radial displacements of the inner and outer specimen wall surfaces measured by the proximity transducers. The most significant radial displacements occurred during the early phase of $\alpha_{\sigma}$ rotation at constant stress ratio (stage 2 of the stress path test).

Figure 15

Figure 16 (a) and (b)

Also included in Figure 16 are the radial wall displacements calculated on the basis of the axial deformation and volume changes of the entire specimen and its inner bore cavity that were measured by the external instrumentation. The volume-change measurements were corrected for the effects of membrane penetration (rubber membranes enclosing the specimen wall surfaces were $0.38 \mathrm{~mm}$ in thickness) using the Sivathayalan and Vaid (1998) method which had been coded in the UCD HCA control program (Naughton and O'Kelly (2003); O'Kelly and Naughton (2005a, c)). Figure 17 shows the mean radial and circumferential normal strains calculated from the wall displacements in Figure 16 using Eqs. 1 and 2. The wall displacements, and hence the radial and circumferential normal strains, calculated based on the external measurements were significantly different from the true values given by the local (proximity transducer) measurements. Significant errors in the external measurements occurred due to inaccuracies in measuring the volume changes of the specimen and its inner bore cavity; specimen end-restraint and bedding effects and the fact that the wall displacements are calculated on the basis that the entire specimen deforms uniformly as a right cylinder. The error is compounded in the case of the radial displacement of the outer specimen wall since its mean value calculated on the basis of two volume-change measurements rather than a single volume-change measurement in the case of the inner wall displacement) (Figure 16(b)).

Figure 17 (a) and (b)

Figure 18 shows the torsional shear strain response during shearing (stage 4 of the stress path test). The true strain response was calculated using Eq. (4 and 5) and the doubleaxes inclinometer radius $r_{\text {incl }}$ value given by Eq. (14) for the UCD set up. Also plotted in Figure 18 is the torsional shear strain response calculated based on the measured outer 
specimen radius instead of the radius $r_{\text {incl }}$ values for the double-axes inclinometers. The torsional shear strain values calculated on the basis of the measured radius $r_{0}$ overestimated the true values by about $90 \%$, which would lead to a significant underestimation of the shear modulus $(G)$ value. The error is particularly large for the UCD setup due to the relatively small outer specimen radius (initially $50.0 \mathrm{~mm}$ ) and the relatively large distance $d$ between the centre of the electrolevel capsules and the outer specimen wall surface.

Figure 18

In the case of the single-axis inclinometer, the radius $r_{\text {incl }}$ and the outer specimen radius $r_{o}$ are simply related by Eq. (6), with the distance $d=15.0 \mathrm{~mm}$ for the UCD setup. The true torsional shear strain values are overestimated by about $30 \%$ by incorrectly using the measured radius $r_{o}$ value instead of the radius $r_{\text {incl }}$ values in Eq. (5), and in general, the error reduces in magnitude as the $r_{\text {incl }}$ to $r_{o}$ ratio approaches unity (i.e. for specimens having larger outer radius).

The test-specimen was initially cross-anisotropic (due to its inherent and induced fabrics produced by the specimen preparation technique and anisotropic consolidation stage 1, respectively). Stages 2 and 3 of the stress path test were designed to study the effects of $\alpha_{\sigma}$ rotation on the orientations to the vertical direction of the major principal stress and strain increments, $\alpha_{\Delta \sigma}$ and $\alpha_{\Delta \varepsilon}$, respectively (Figure 19). As $\alpha_{\sigma}$ rotates during stage 2, $\alpha_{\Delta \sigma}$ initially increased rapidly from $\alpha_{\Delta \sigma}=0$ to about $75^{\circ}\left(\alpha_{\sigma} \leq 3^{\circ}\right)$ before reducing back sharply and following $\alpha_{\Delta \sigma} \cong \alpha_{\sigma}+43^{\circ}$ over the range $3^{\circ}<\alpha_{\sigma} \leq 45^{\circ}$ (Figure 19(a)). $\alpha_{\sigma}, \alpha_{\Delta \sigma}$ and $\alpha_{\Delta \varepsilon}$ are also plotted against the step number for stages 1 to 3 in Figure 19(b). $\alpha_{\Delta \sigma}$ quickly reduced once $\alpha_{\sigma}$ rotation stopped on reaching the target $45^{\circ}$ value at the end of stage 2 and, in accordance with the stress path, $\alpha_{\sigma}$ and $\alpha_{\Delta \sigma}$ remained coincident, orientated at $45^{\circ}$ to the vertical direction throughout stages 3 and 4 .

Note that $\alpha_{\Delta \varepsilon}$ always remained significantly smaller than $\alpha_{\Delta \sigma}$ during $\alpha_{\sigma}$ rotation with $\alpha_{\Delta \varepsilon}$ generally tending to lie between $\alpha_{\sigma}$ and $\alpha_{\Delta \sigma}$ (Figure 19(b). However, as $\alpha_{\sigma}$ approached $45^{\circ}$ (and with $\alpha_{\Delta \sigma}$ approaching $88^{\circ}$ ), $\alpha_{\Delta \varepsilon}$ tended to reduce back to a near vertical direction $\left(\alpha_{\Delta \varepsilon} \cong 5^{\circ}-10^{\circ}\right)$. $\alpha_{\Delta \varepsilon}$ increased again to $\alpha_{\Delta \varepsilon} \cong 31^{\circ}$ throughout stage 3 (with $\alpha_{\sigma}$ maintained at $45^{\circ}$ ) and the non-coincidence of $\alpha_{\sigma}$ and $\alpha_{\Delta \varepsilon}$ is indicative of an anisotropic specimen. The $\alpha_{\Delta \sigma}$ and $\alpha_{\Delta \varepsilon}$ responses presented follow the same general trends reported for similar stress path tests on clean medium-sized sand in the IC HCA by Hight et al. (1983).

Figure 19

\section{Summary and conclusions}

One single-axis and two double-axes inclinometers and two proximity transducers accurately measure the polar deformation response (pseudo-elastic range to failure 
condition) over the uniformly-stressed zone within the mid-third of the specimen length in the University College Dublin (UCD) hollow cylinder apparatus (HCA). The doubleaxes inclinometers were reconfigured (reduced gauge length of $45 \mathrm{~mm}$ compared to 120 $\mathrm{mm}$ in the original Imperial College design) in order to suit the more compact pressurecell and smaller test-specimen size in the UCD HCA.

The non-contact proximity transducers can be relocated using precision gearing from outside the pressure-cell during the course of a test to suit the specimen deformation response. Another novel feature is that neither the outer cell chamber nor the specimen bore cavity experience a volume change on relocating the inner proximity transducer.

The instruments were calibrated using an optical table and a laser distance-measurement system to achieve the necessary accuracy for strain measurements over the pseudoelastic range. The proximity transducers must be calibrated while submerged in water (in-service condition) since the transducer response is affected by the operating medium (calibration data for the in air and in water conditions differed by about $1.5 \%$ full scale: a significant error for small-strain measurements. The calibration curves for the proximity transducers were non-linear and strongly affected by the specimen wall curvature, particularly for the outer wall surface (convex target). The inclinometer outputs were linear for axial displacement alone and for tilt displacement alone over a reduced mid-measurement range allowing multi-linear regression analysis of the data recorded during generalized stress path tests.

The axial and twist deformations of the specimen were calculated on the basis of the inclinometer tilt angle $\phi_{\text {incl }}$ measured in the circumferential direction along an arc of radius $r_{\text {incl }}$ (i.e. beyond the outer specimen wall surface). Equations have been presented to calculate the radius $r_{i n c l}$, and hence the true torsional shear strain response, from the inclinometer gauge and radial tilt angle and the dimensions and axial deformation response of the specimen (taking into consideration the linkage articulation as the specimen deforms under loading).

After correcting for membrane penetration effects, the external measurements (in particular the radial displacement of the outer specimen wall) still included significant errors due to apparatus compliance, specimen end-restraint and bedding effects, inaccuracies in measuring volume changes and the fact that the calculations assume that the entire specimen deforms uniformly as a right cylinder.

The set up and calibration of the local instrumentation used in this study can be equally applied to provide cost-effective, reliable and accurate distance-measurement systems in other HCAs and for other geotechnical laboratory applications.

\section{Acknowledgments}

The authors would like to thank Dr. Tom Widdis and Professor Eugene O'Brien (University College Dublin) for their support during the course of this research. The authors would also like to acknowledge the many informative discussions with Mr. Steve Ackerley (Imperial College, London). The paper was written by the first author 
while on sabbatical leave at the Urban Institute Ireland, University College Dublin. The first author is also grateful for funding received through the Pierse-Newman Scholarship in Civil Engineering during the course of this research at University College Dublin.

\section{References}

Ampadu, S.K. and Tatsuoka, F., 1993. A hollow cylinder torsional simple shear apparatus capable of a wide range of shear strain measurement. Geotechnical Testing Journal, 16(1), 3-17.

Baldi, G., Hight, D.W. and Thomas, G.E., 1988. A reevaluation of conventional triaxial test methods. In: Advanced Triaxial Testing of Soils and Rock, ASTM STP977. Philadelphia, USA: American Society for Testing and Materials.

Brown, S.F., Austin, G. and Overy, R.F., 1980. An instrumented triaxial cell for cyclic loading of clays. Geotechnical Testing Journal, 3(4), 145-152.

Burland, J.B. and Symes, M., 1982. A simple axial displacement gage for use in the triaxial apparatus. Géotechnique, 32(1), 62-65.

Clayton, C.R.I. and Khatrush, S.A., 1986. A new device for measuring local axial strains on triaxial specimens. Géotechnique, 36(4), 593-597.

Connolly, T.M. and Kuwano, R., 1999. The measurement of $\mathrm{G}_{\max }$ in a resonant column, bender elements, torsional shear apparatus. In: Proceedings of the International Conference on the Pre-failure Deformation Characteristics of Geomaterials, Torino (Italy), 1999, 1, 73-80.

Cuccovillo, T. and Coop, M.R., 1997. The measurement of local axial strains in triaxial tests using LVDTs. Géotechnique, 47(1), 167-171.

Hight, D.W., Gens, A. and Symes, M.J., 1983. The development of a new hollow cylinder apparatus for investigating the effects of principal stress rotation in soils. Géotechnique, 33(4), 355-383.

Hird, C.C. and Yung, P.C.Y., 1989. The use of proximity transducers for local measurements in triaxial tests. Geotechnical Testing Journal, 12(4), 292-296.

Huang, A.B., Huang, Y.T., Tai Y.Y., Ho, F.J. and Chang, J.M., 2007. Quadruple LVDT local rotational displacement measurement in torsional shear tests. Journal of Geomechanics and Geoengineering, 2(4), 109-115.

Jardine, R.J., Symes, M.J. and Burland, J.B., 1984. The measurement of soil stiffness in the triaxial apparatus. Géotechnique, 34(3), 323-340.

Kaman Instrumentation Corporation (USA), 1986. Application of a precision measurement technology. Kaman Measuring Systems Seminar Workbook, SWB 865.

Lo Presti, D.C.F., Pallara, O., Lancellotta, R., Armandi, M. and Maniscalco, R., 1993. Monotonic and cyclic loading behavior of two sands at small strains. Geotechnical Testing Journal, 16(4), 409-424.

Menkiti, O.C., 1995. Behaviour of clay and clayey-sand with particular reference to principal stresses rotation. Thesis $(\mathrm{PhD})$. University of London (Imperial College).

Miura, K., Miura, S. and Toki, S., 1986. Deformation behaviour of anisotropic dense sand under principal stress axis rotation. Soils and Foundations, 26(1), 36-52.

Naughton, P.J. and O'Kelly, B.C., 2003. The anisotropy of Leighton Buzzard sand under general stress conditions. In: Proceedings of the 3rd International Symposium on Deformation Characteristics of Geomaterials, Lyon, 2003, 1, 285-292. 
Naughton, P.J. and O'Kelly, B.C., 2004. The induced anisotropy of Leighton Buzzard sand. In: Advances in Geotechnical Engineering: The Skempton Conference, London (UK), 2004, 1, 556-567.

Naughton, P.J. and O'Kelly, B.C., 2007. Stress non-uniformity in a hollow cylinder torsional sand specimen. Journal of Geomechanics and Geoengineering, 2(2), 117-122. O'Kelly, B.C., 2000. Development of a new apparatus for hollow cylinder testing. Thesis (PhD). University College Dublin, Ireland.

O'Kelly, B.C. and Naughton, P.J., 2003. Development of a new hollow cylinder apparatus for generalised stress path testing. Ground Engineering, 36(7), 26-28.

O'Kelly, B.C. and Naughton, P.J., 2005a. Closed-loop control of a hollow cylinder apparatus. In: Proceedings of the Symposium on Innovative Experimental Techniques at the ASCE/ASME/SES Conference on Mechanics and Materials (McMat2005), Baton Rouge, Louisiana (USA), 2005.

O'Kelly, B.C. and Naughton, P.J., 2005b. Development of a new hollow cylinder apparatus for stress path measurements over a wide strain range. Geotechnical Testing Journal, 28(4), 345-354.

O'Kelly, B.C. and Naughton, P.J., 2005c. Engineering properties of wet-pluviated hollow cylindrical specimens. Geotechnical Testing Journal, 28(6), 570-576.

Rechenmacher, A.L. and Finno, R.J., 2004. Digital image correlation to evaluate shear banding in dilative sands. Geotechnical Testing Journal, 27(1), 13-22.

Scholey, G.K., Frost, J.D., Lo Presti, D.C.F. and Jamiolkowski, M., 1995. A review of instrumentation for measuring small strains during triaxial testing of soil specimens. Geotechnical Testing Journal, 18(2).

Sivathayalan, S. and Vaid, Y.P., 1998. Truly undrained response of granular soils with no membrane penetration effects. Canadian Geotechnical Journal, 35, 730-739.

Symes, M.J. and Burland, J.B., 1984. Determination of local displacements on soil samples. Geotechnical Testing Journal, 7(2), 49-59.

Tatsuoka, F., Muramatsu, M. and Saski, T., 1983. Closure to Cyclic undrained stressstrain behaviour of dense sands by torsional simple shear tests. Soils and Foundations, 23(3), 142-145.

Tatsuoka, F., Sonoda, S., Hara, K., Fukushima, S. and Pradhan, T.B.S., 1986. Failure and deformation of sand in torsional shear. Soils and Foundations, 26(4), 79-97.

Vaid, Y.P., Sayao, A., Hou, E. and Negussey, D., 1990. Generalized stress-pathdependent soil behaviour with a new hollow cylinder torsional apparatus. Canadian Geotechnical Journal, 27, 601-616. 
Table (x 1)

Table 1. Range, resolution and output of local instrumentation.

\begin{tabular}{llll}
\hline Deformation & Range & Resolution & Output \\
\hline Axial & -20 to $20 \mathrm{~mm}$ & $1.0 \times 10^{-4} \mathrm{~mm}$ & -1.0 to 1.0 volt \\
Radial & $6 \mathrm{~mm}$ & $1.1 \times 10^{-6} \mathrm{~mm}$ & -5.0 to 5.0 volt \\
Twist & $-30^{\circ}$ to $30^{\circ}$ & $1.0 \times 10^{-4}$ degree & -0.5 to 0.5 volt \\
\hline
\end{tabular}

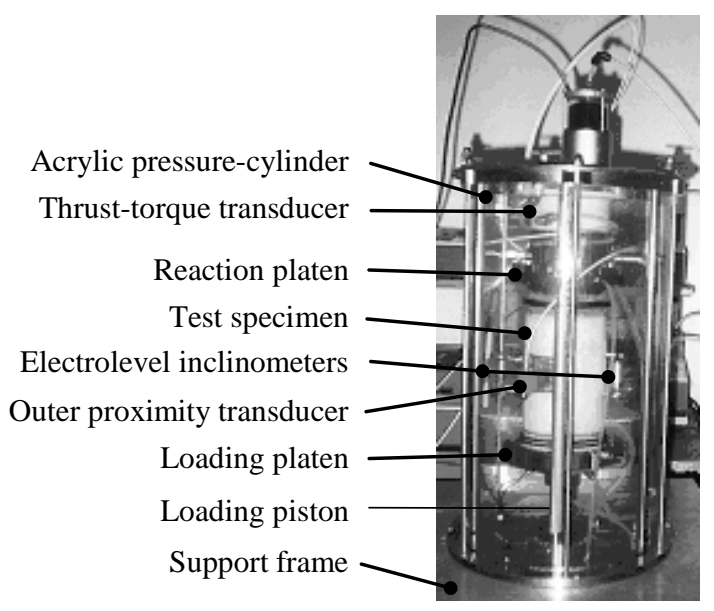

Figure 1. Pressure cell of UCD hollow cylinder apparatus.

(a)

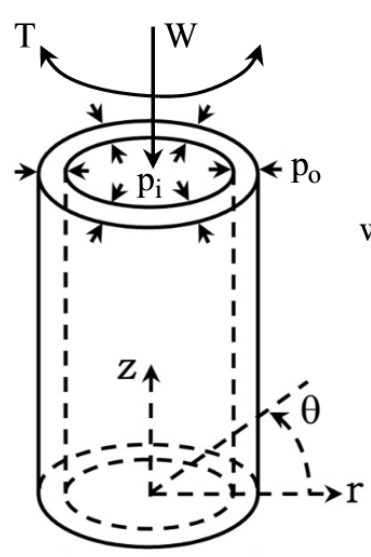

(b)

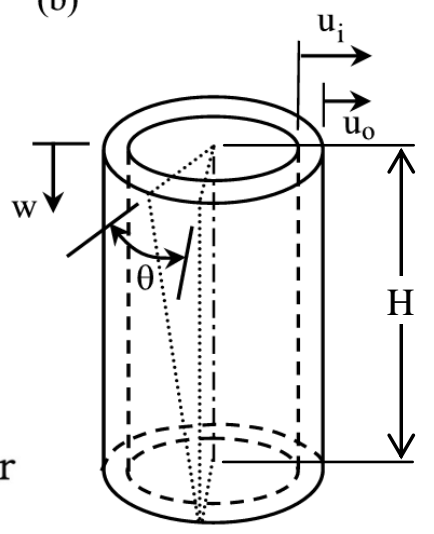

(a) Applied loads and confining pressures.

(b) Specimen deformation response.

Figure 2. Hollow cylindrical test-specimen. 


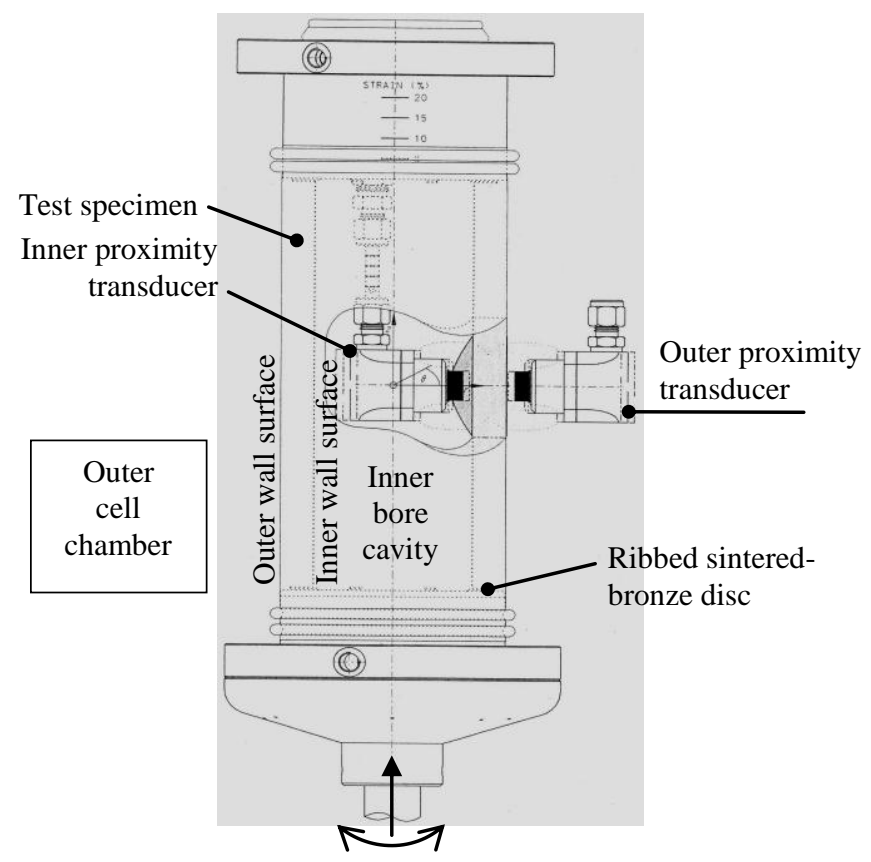

Figure 3. Setup of proximity transducers inside and outside the specimen.

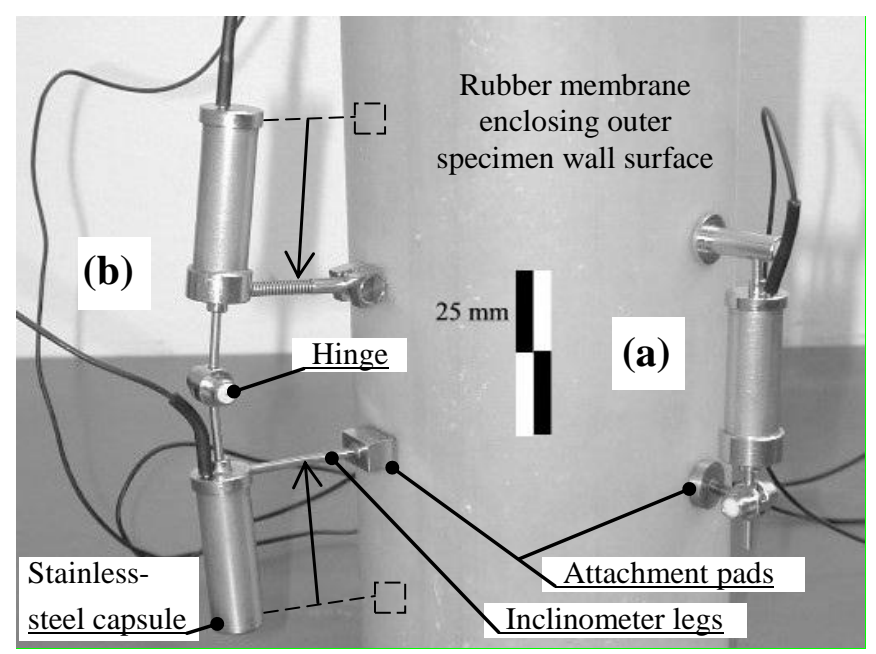

Figure 4. UCD inclinometer configurations: (a) Single axis; (b) Double axes. 


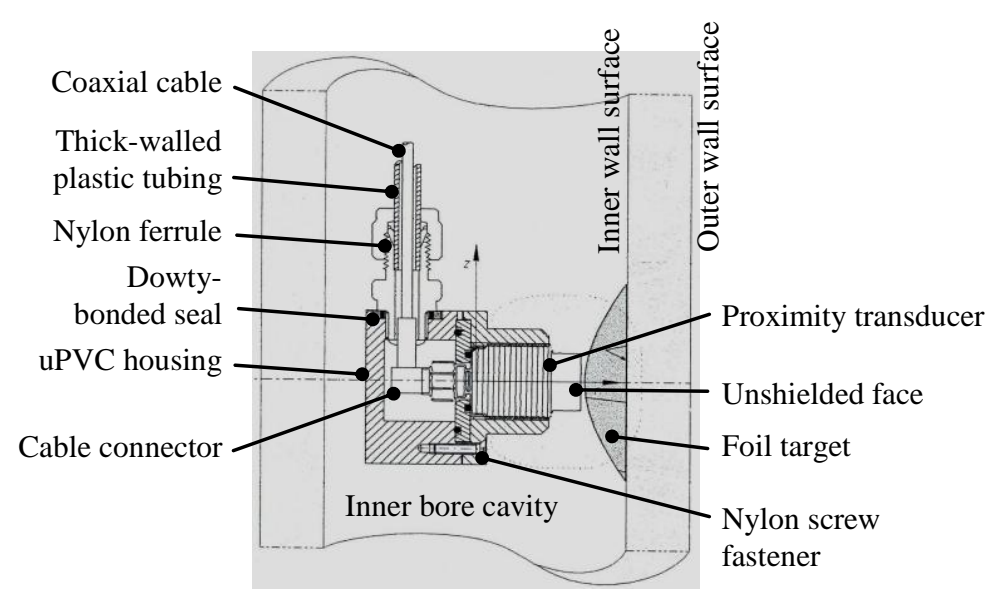

Figure 5. Section through the inner proximity transducer.

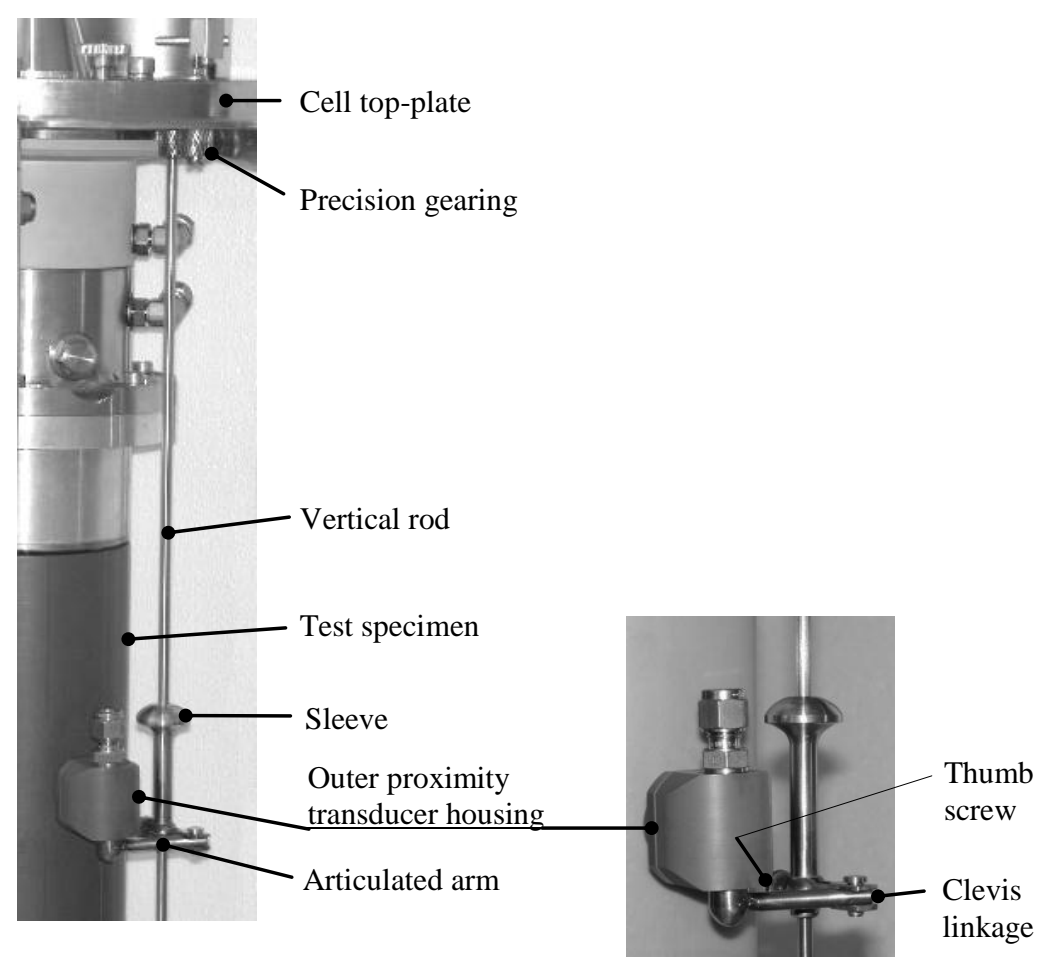

(a) Mechanism.

(b) Housing support.

Figure 6. Mechanism that locates the outer proximity transducer. 


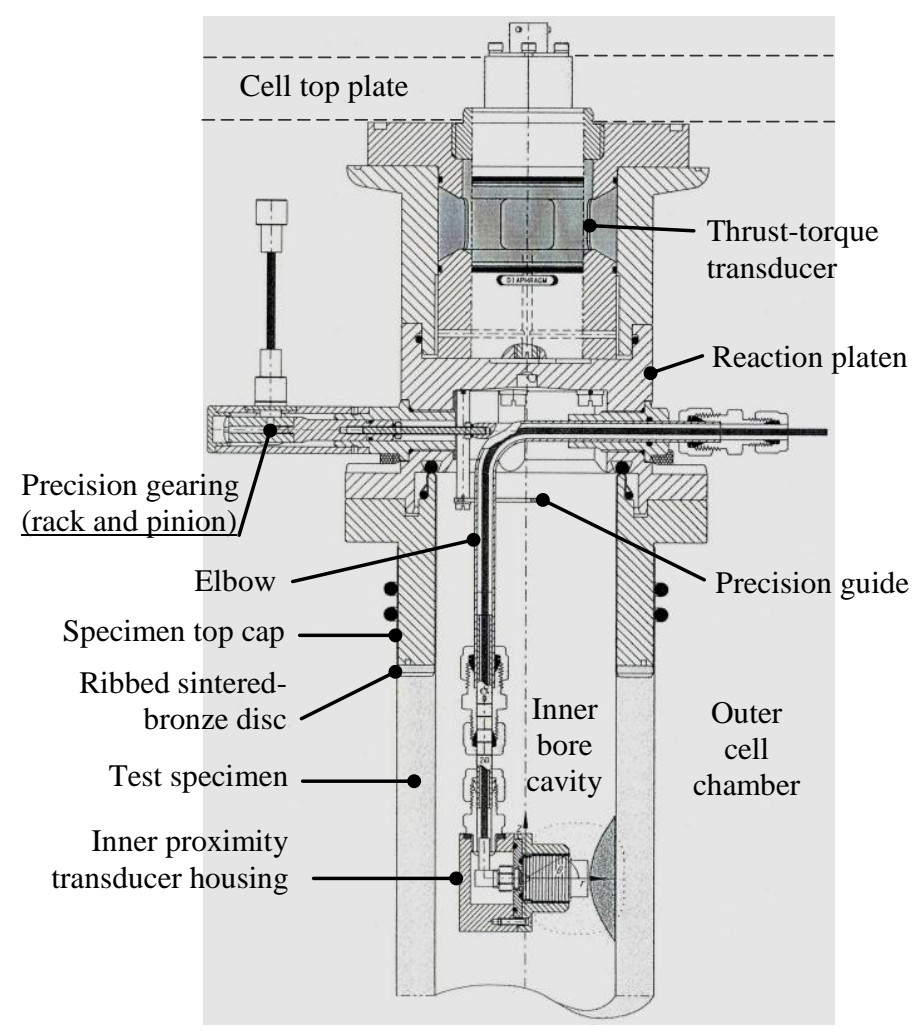

Figure 7. Mechanism that locates the inner proximity transducer.

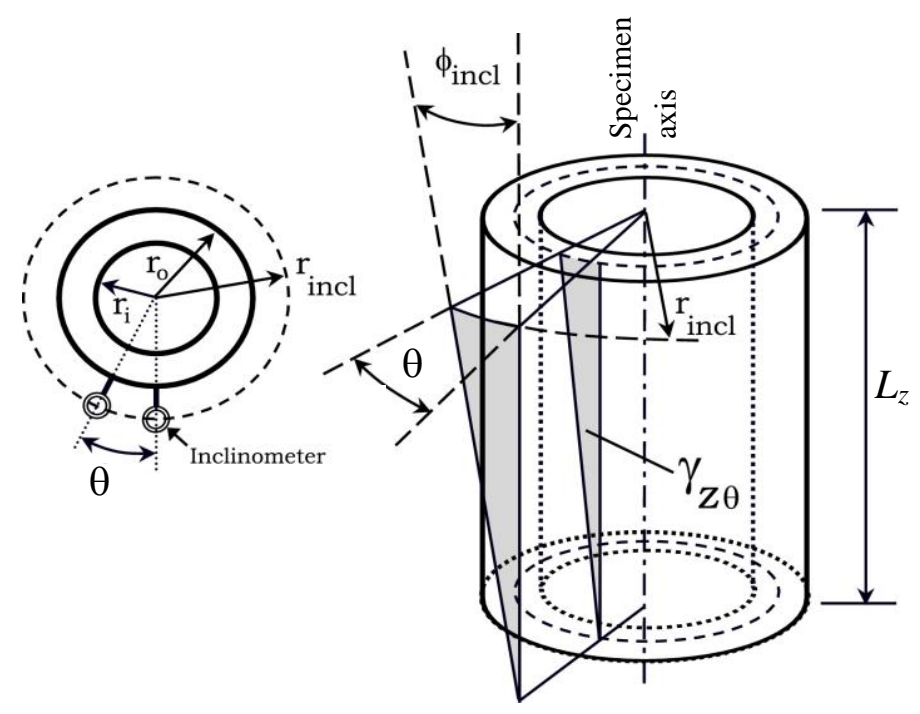

Figure 8. Twist deformation measured by inclinometer (adopted from Connolly and Kuwano 1999). 


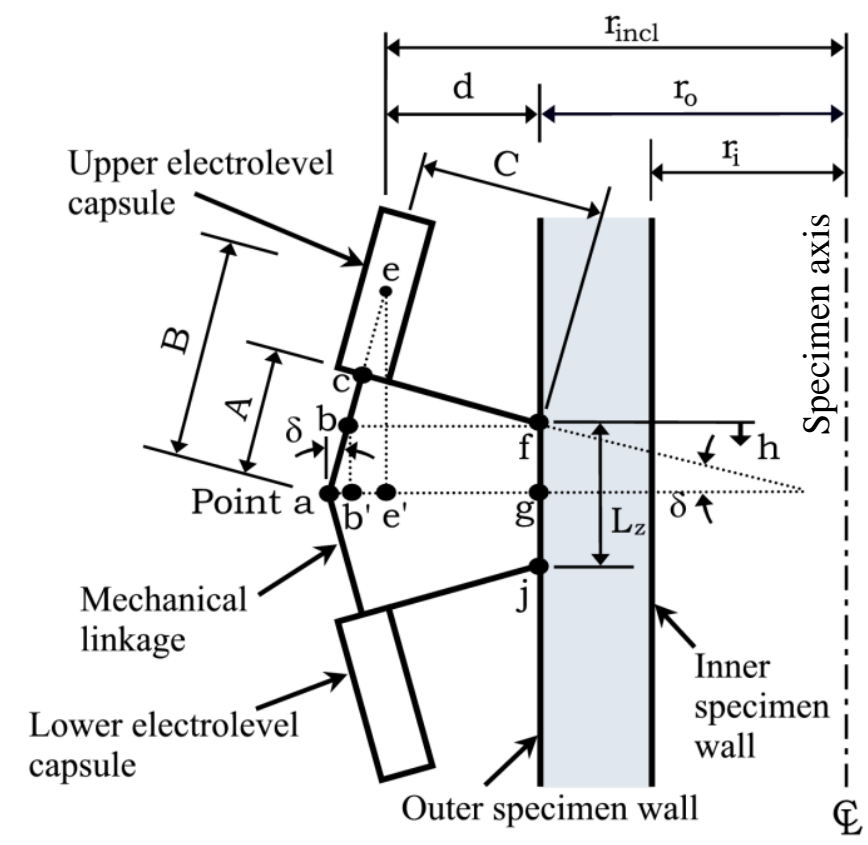

Points $f, j$ are points of attachment to outer specimen membrane

Points $\mathrm{a}, \mathrm{f}$ are hinges that allow free movement in vertical plane

Inclinometer leg fc allows rotation about its own axis

Point $\mathrm{j}$ is a universal pivot

Figure 9. Configuration of UCD double-axes inclinometer. 


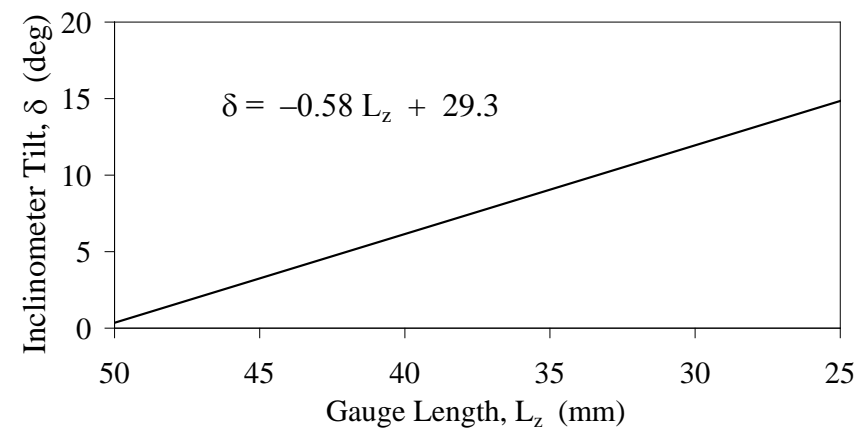

(a) Tilt angle $\delta$ and gauge length.

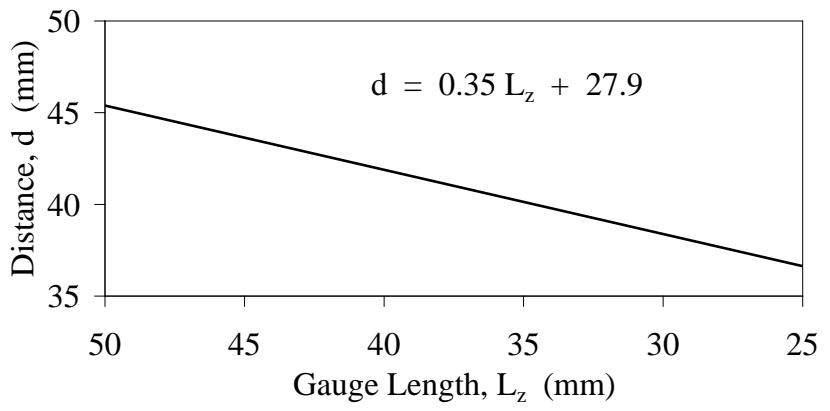

(b) Distance d and gauge length.

Figure 10. Relationships for UCD double-axes inclinometer.

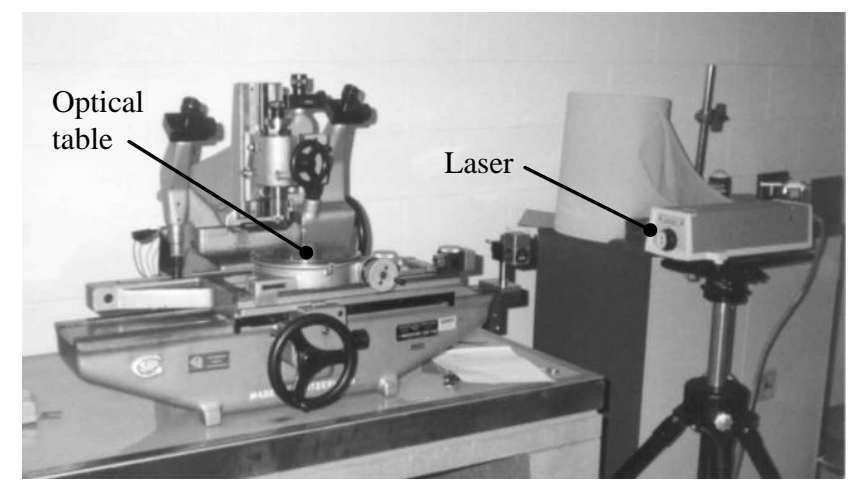

Figure 11. Optical table and laser distance-measurement system. 


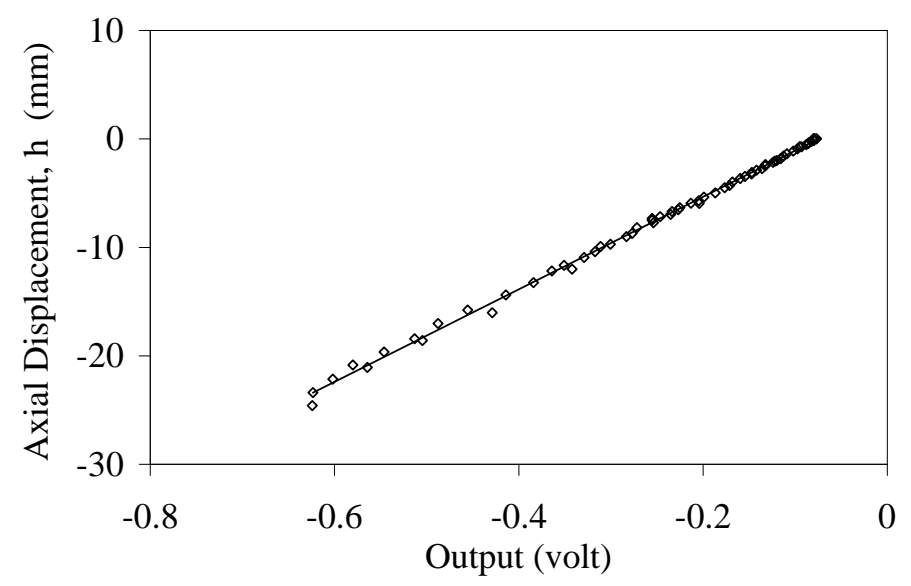

(a) Axial displacement alone of double-axes inclinometer.

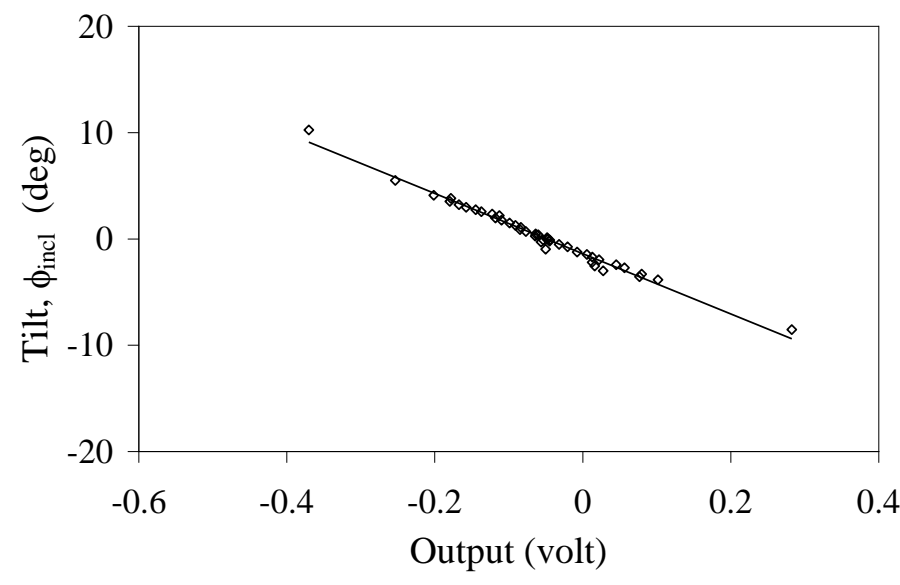

(b) Tilt displacement alone of double-axes inclinometer.

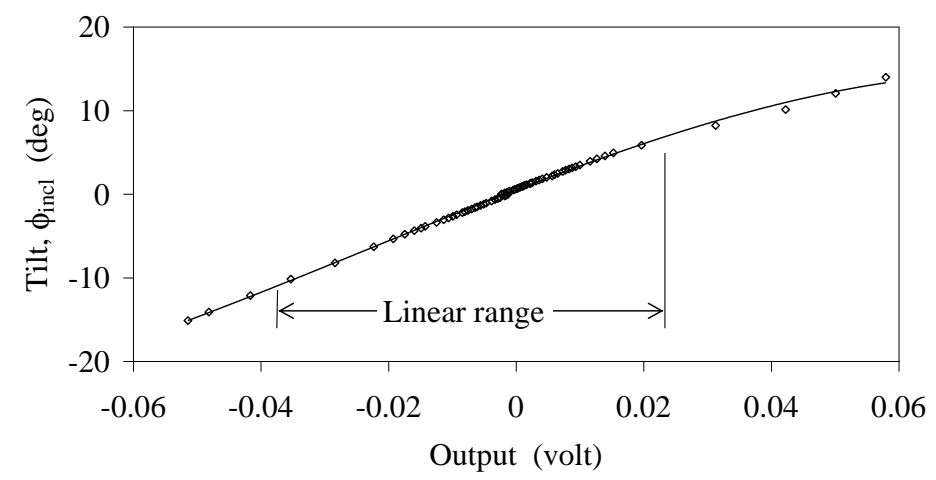

(c) Tilt displacement of single-axis inclinometer.

Figure 12. Calibration data for UCD inclinometers. 


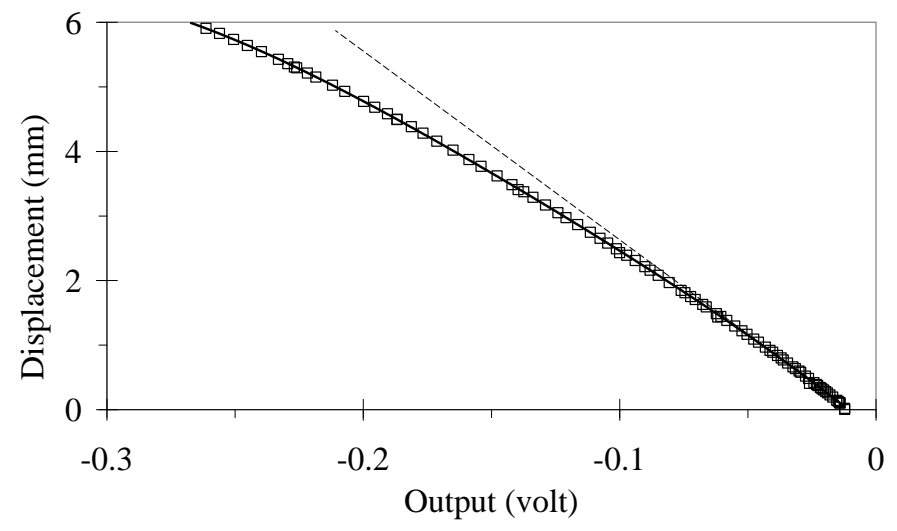

(a) Outer transducer and convex target.

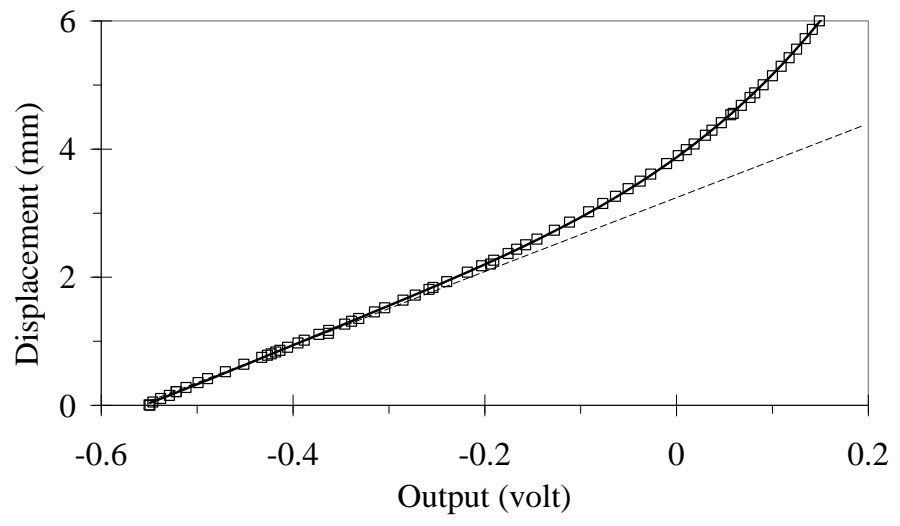

(b) Inner transducer and concave target.

Figure 13. Calibration data for proximity transducers. 


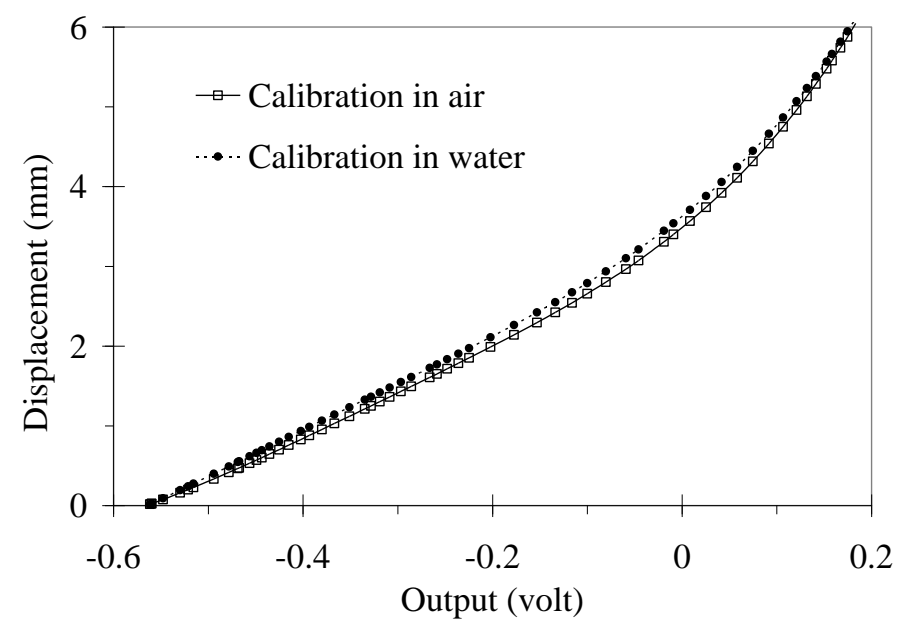

Figure 14. Calibration of proximity transducers in air and in water.

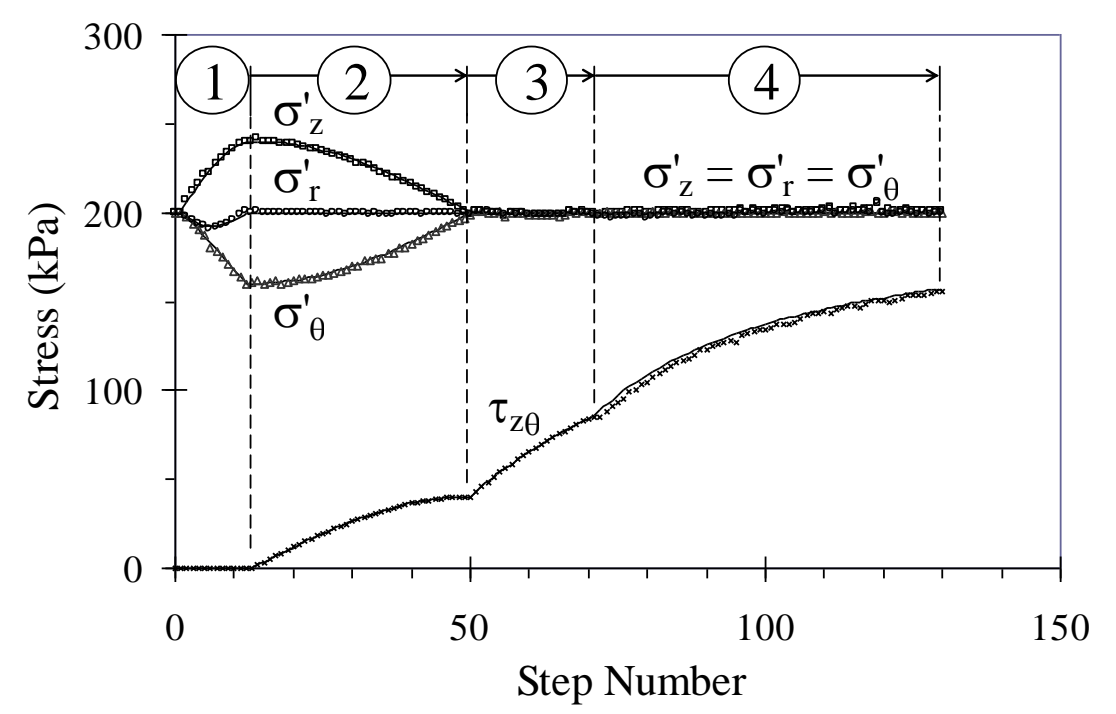

Figure 15. Smooth variation of stress components in targeting the stress path. 


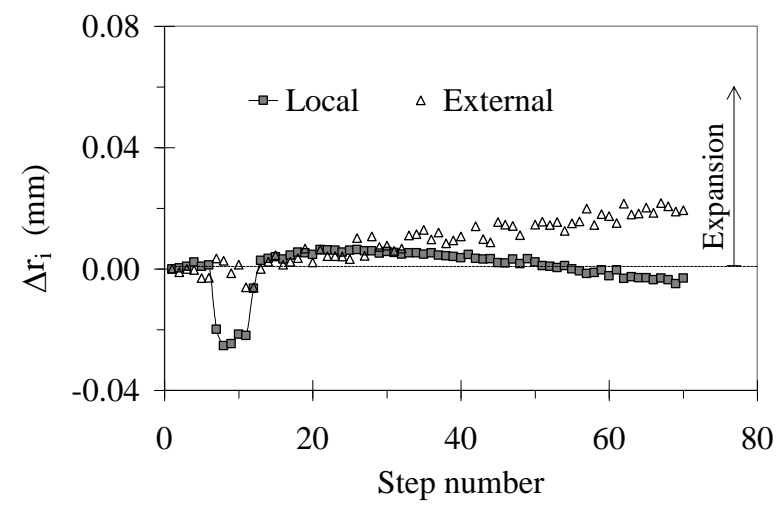

(a) Inner wall surface.

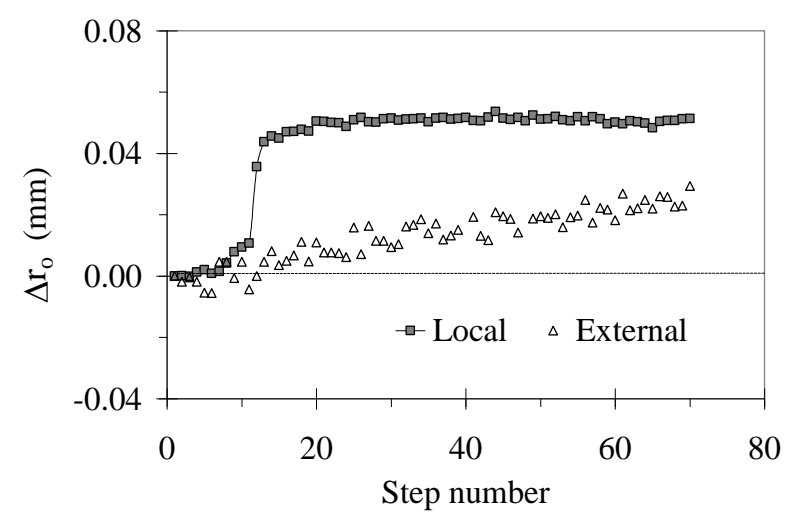

(b) Outer wall surface.

Figure 16. Radial displacements of the specimen wall surfaces during stages 1 to 3 of the stress path test. 


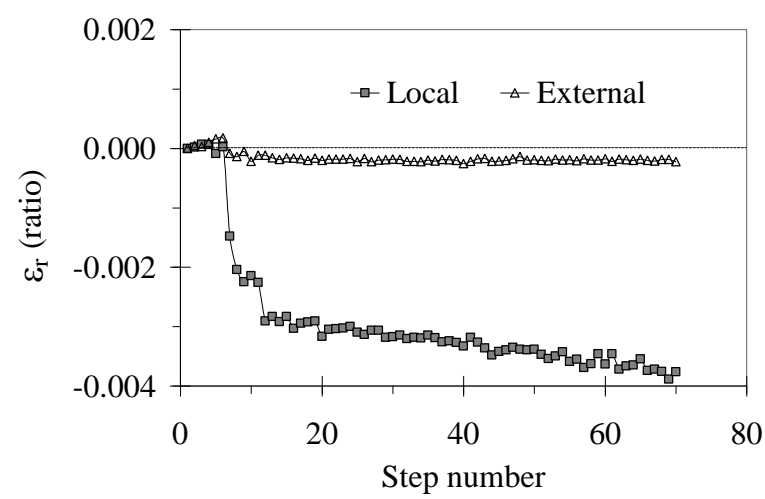

(a) Mean radial normal strain.

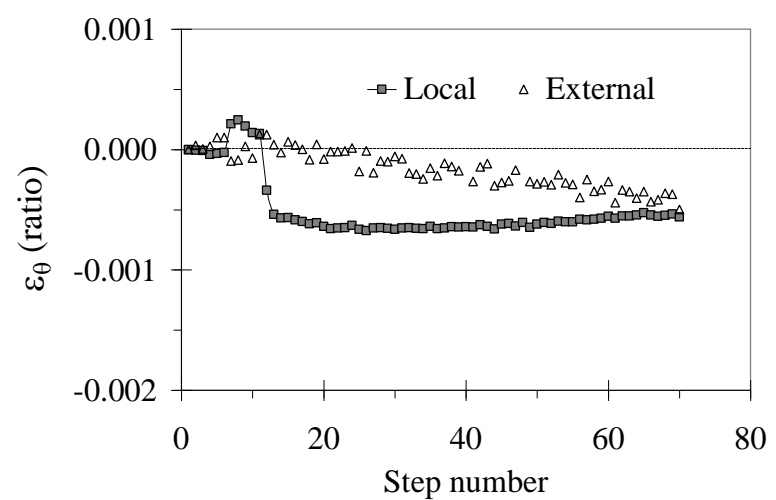

(b) Mean circumferential normal strain.

Figure 17. Strain response during stages 1 to 3 of the stress path test.

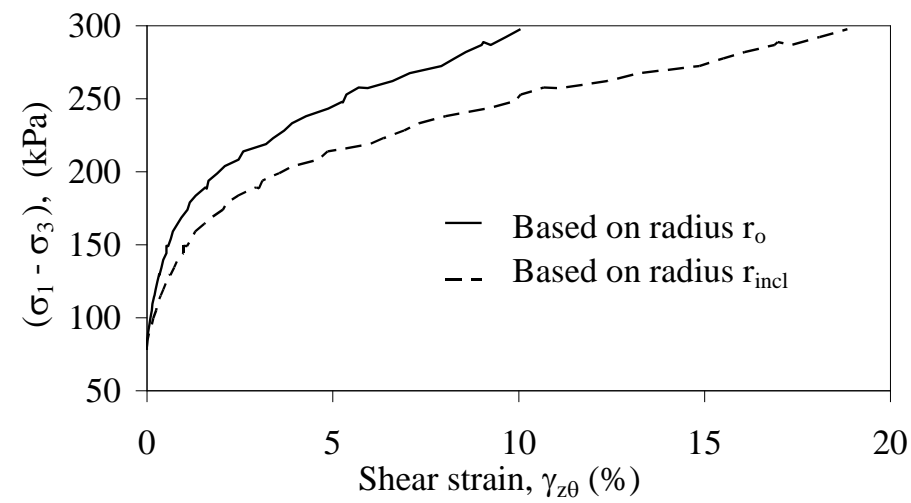

Figure 18. Torsional shear strain measurements from inclinometers during stage 4 of the stress path test. 


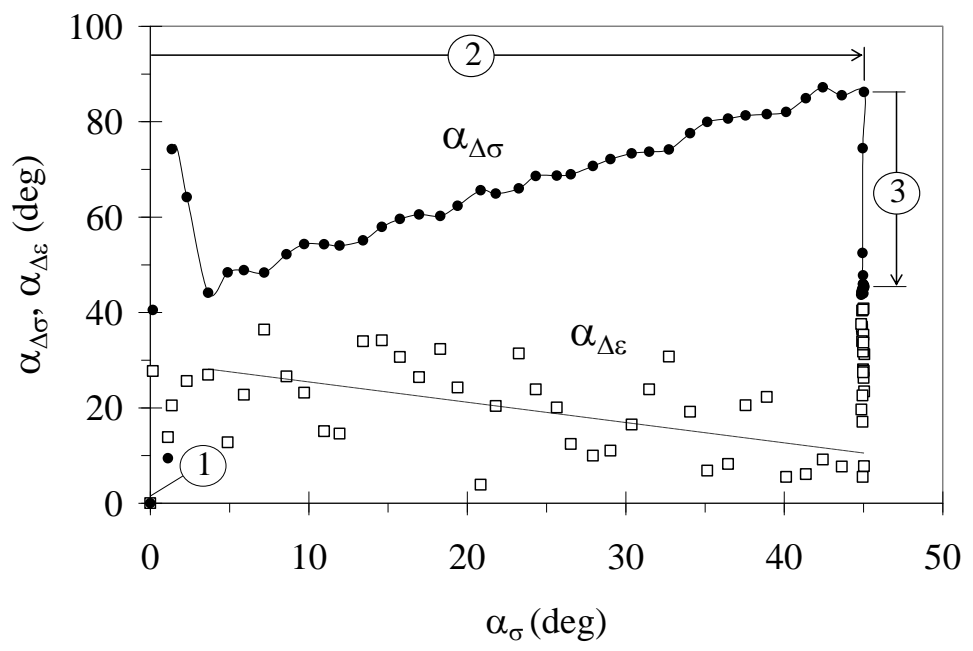

(a) During $\alpha_{\sigma}$ rotation.

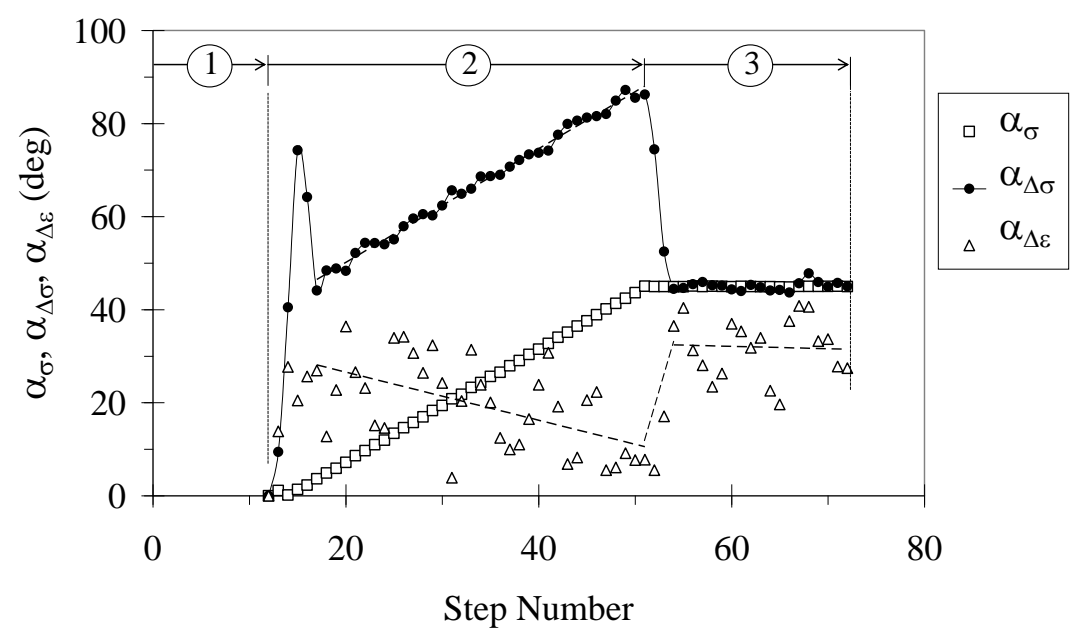

(b) At intermediate points along the stress path.

Figure 19. Orientations of the major principal stress and strain increment directions during stages 1 to 3 of the stress path test. 